\title{
School Belonging in Different Cultures: The Effects of Individualism and Power Distance
}

\author{
Kai S. Cortina ${ }^{1 *}$, Sari Arel ${ }^{1}$ and Joanne P. Smith-Darden ${ }^{2}$ \\ ${ }^{1}$ University of Michigan, Ann Arbor, MI, United States, ${ }^{2}$ Wayne State University, Detroit, MI, United States
}

Limited evidence exists on how the larger cultural framework affects psychological processes related to schooling. We investigated how the cultural dimensions of individualism/collectivism and power distance influence the sense of school belongingness using 2003 Programme for International Student Assessment survey data on 15-year-old students from 31 countries. Hierarchical linear modeling analysis indicated that power distance (i.e., hierarchical nature of social relationships) is a better predictor of school belongingness on the cultural level than individualism/collectivism. Accordingly, students living in cultures with high degree of power distance (particularly East Asian countries in these data sets) report lower school belongingness than students living in cultures with more lateral power relationships (Western countries). Positive teacher student relations and preference for cooperative learning environment predict higher school belongingness across cultures.

Barbara McCombs, University of Denver,

United States

Reviewed by: Mauro Murgia,

University of Trieste, Italy Stefanie Chye,

Nanyang Technological University, Singapore

*Correspondence: Kai S. Cortina schnabel@umich.edu

Specialty section:

This article was submitted to Educational Psychology, a section of the journal Frontiers in Education

Received: 17 April 2017 Accepted: 05 October 2017 Published: 01 November 2017

Citation:

Cortina KS, Arel S and SmithDarden JP (2017) School Belonging in Different Cultures: The Effects of Individualism and Power Distance.

Front. Educ. 2:56.

doi: 10.3389/feduc.2017.00056
Keywords: sense of school belonging, cross-cultural research, PISA, adolescents, teacher-student relationship

\section{INTRODUCTION}

Baumeister and Leary (1995) have argued that the need for social affiliation is universal although the way it is expressed may differ across cultures. The efforts people make to establish and maintain social relationships cannot be explained by economic benefits (i.e., safety and nutrition) and thus are likely to be carried out to satisfy the "need for belongingness." Experiencing a sense of social belongingness has been linked to positive emotions (e.g., happiness), while being deprived of a sense of belonging has been linked to a variety of negative outcomes, such as higher levels of mental and physical illness (see Baumeister and Leary, 1995).

Besides the family, school is the most important developmental setting for adolescents (Eccles and Roeser, 2011), and a growing body of literature highlights psychological benefits of experiencing psychological belongingness in school (e.g., Ryan and Deci, 2000; Anderman, 2002; Patrick et al., 2002). School belongingness is usually defined as the feeling of connectedness with the school community, and it is assumed to contribute to academic motivation constructs, such as engagement and self-efficacy which, in turn, improve academic achievement (Goodenow, 1993; Osterman, 2000; Furrer and Skinner, 2003; Kia-Keating and Ellis, 2007; Roseth et al., 2008). Perceiving school as a caring community has also been reported to be positively related to students' attitude towards schooling, educational aspirations, and respect and trust in teachers (Battistich et al., 1997), as well as to act as a protective factor against delinquent behavior, substance abuse, and depression among students (Battistich and Hom, 1997; Anderman, 2002; Napoli et al., 2003). While the empirical research activity has slowed down somewhat over the last decade, there are conceptual issues that are 
worth further investigation because sense of belongingness has a strong cultural component, particularly in the school context. Kumar and Maehr (2010) have argued that even within the same school students from different cultural backgrounds are likely to experience school differently. Research suggests, for example, that Asian and Hispanic students report higher levels of school belongingness than white and African American students in the USA (Battistich and Hom, 1997) and that peer relations and teacher-student relations differed in their salience as a predictor of overall school belongingness for these groups (Faircloth and Hamm, 2005). Other studies, however, have found that immigrant and minority students report lower levels of school belongingness than nonimmigrant and majority students in Europe (Houtte and Stevens, 2009) and in the USA (Alvarez et al., 2007). Despite the inconclusive findings, it is clear that there is an increasing interest in the cultural factors that affect sense of school belonging within a country. To our knowledge, no study has yet assessed this cross-nationally. In the present study, we focus on comparisons between East Asian countries and countries of culturally Western heritage.

Goodenow (1993) has argued that school belongingness is neither purely intrapersonal nor exclusively contextual, but rather emerges from the interaction of a given person within a particular environment. It is thus appropriate to investigate school belongingness simultaneously as a measure of individual closeness to the school and as an indicator of the quality of the learning environment on the classroom and school level. While most of the variability in students' sense of belongingness lies between individuals (Anderman, 2002), Battistich et al. (1997) found that up to $15 \%$ of the variability in sense of belongingness lies between schools and another $15 \%$ between classrooms, indicating substantial context effects.

Ecological theory (Bronfenbrenner, 1977, 1979) predicts that variables of the microsystem (e.g., schools) have a more immediate influence on the individual than the surrounding macrosystems (e.g., culture) which exerts influence mainly through mediating institutions (e.g., school curriculum). Accordingly, while students are most directly influenced by teachers, peers, and parents during their school day, they are, nevertheless also influenced by the political, economic, cultural, and interpersonal macro environment inasmuch these factors affect schools, teachers, parents, and peers (Sarason, 1990; Eccles and Roeser, 1999; Hamm and Zhang, 2010). To understand the influence of the larger cultural context and the school context, we integrate the work on the self and interpersonal relationships by Markus and Kitayama (1991, 2010), Kitayama et al. (2000), and cultural dimensions theory introduced by Hofstede et al. (2010).

\section{Cultural Psychology Perspective}

A striking difference between Western and East Asian societies is the way "self" is defined in relation to others (Markus and Kitayama, 2010; Kitayama et al., 2010; Kitayama and Uskul, 2011). The Western culture is usually described as individualistic, and people are characterized as having a more independent view of the self (Kitayama et al., 2000; Kitayama and Uskul, 2011). An individual is seen as consisting primarily of personal attributes such as personality traits, beliefs, and attitudes. Consistently, child-rearing practices in Western societies emphasize the importance of self-reliance, independence, and personal choice (Triandis, 1989; Fiske et al., 1998), and social situations are seen as affirming sources of the core of the independent self (Markus and Kitayama, 1991).

East Asian cultures, in turn, are often described as communal, and the people as having an interdependent view of the self. ${ }^{1}$ Attributes used to describe a person emphasize connectedness with others, e.g., empathy and kinship (Gudykunst and Nishida, 1986; Fiske et al., 1998). Members of collectivist cultures see themselves more as a part of social relationships and consider their actions and cognitions as largely affected by the perceived thoughts and anticipated behaviors of significant others (Kitayama et al., 2000). When compared with members of individualistic cultures, Markus and Kitayama (1991) note that sense of belonging can become so strong that it makes sense to think of the relationship instead of the self as the functional unit of conscious reflection.

Another difference that follows from this distinction is that people in individualistic cultures tend to give priority to their personal goals over in-group goals, while people in collectivist cultures tend to do the opposite (Triandis, 1989, 2001). For the school context this means that in individualistic cultures the student is deemed responsible for and focused on his or her school work, while in collectivist cultures larger groups (family, teachers, and classmates) are expected to assume a large share of this responsibility. Correspondingly, the success of the group as a whole is valued as highly as or even higher than the success of the individuals within the group (Stevenson and Lee, 1990). Thus, in collectivist cultures achievement motivation may not be accurately described as an individual, competitive drive.

In summary, collectivist cultures emphasize social connectedness, interdependence, and in-group goals; while individualistic cultures emphasize self-reliance, independence and personal goals. From the cross-cultural literature for the present question regarding school belongingness we would predict that students living in East Asian collectivist cultures should report higher school belongingness than students living in Western, individualistic cultures.

\section{Cultural Dimensions Theory}

Hofstede's (Hofstede, 2001) and Hofstede et al. (2010) cultural dimensions have been an influential paradigm for understanding cultural differences for several decades. He argues that culture is "the software of our minds" and that the culture in which we are brought up "programs" our minds to work in ways that are similar to others' brought up in those environments, and different from the minds of those who were raised in other cultures. Hofstede's theoretical framework originated from his observations of different management cultures across countries within the same mother company and survey studies Hofstede et al. (2010). Hofstede's theory maintains that work environments

${ }^{1}$ While in this paper the East Asian countries we focus on can be described as collectivist, we would like to note that these characterizations are not synonyms. For example Singapore is an example of an East Asian country that cannot be easily categorized as collectivist or individualist. Similarly, not all culturally Western countries adhere to individualistic values to the same degree. 
are culture-bound on four statistically independent dimensions: power distance, uncertainty avoidance, individualism, and masculinity. He later added a fifth dimension, long-term orientation. He argues that these dimensions apply not only to work places, but also to other institutions within a culture, including the family and schools (Hofstede, 2001; Hofstede et al., 2010).

Power distance refers to the power inequality between superiors and subordinates, so that cultures high in this dimension have an obvious hierarchy in organizations. Uncertainty avoidance refers to tolerance of ambiguity and is reflected in higher number of written rules. The dimension of individuality-collectivism refers to the way people think of themselves, conceptualized similar to the equivalent construct in cultural psychology. Masculinity defines gender roles with cultures high on this dimension having few women in top positions. Finally, long-term orientation refers to virtues oriented toward the future (e.g., sense of adaptation to societal challenges) or the present moment at the other end of the dimension (e.g., national pride in status quo, preservation of "face") (Hofstede et al., 2010).

Although Hofstede's dimensions were derived from data gathered at the work place, they have been used in multiple studies examining cultural differences in schooling. The dimensions have been found to have predictive power in academic adjustment and social integration (Rienties and Tempelaar, 2013), learning style preference (Sugahara and Boland, 2010), and school principals' reports of aggressive behavior among students (Bergmüller, 2013). In line with these studies, we argue that school is an example of an organizational context which differs from culture to culture in exactly the same way as work place context.

Of the five cultural dimensions suggested by Hofstede power distance seems particularly salient to schooling. Power distance is sensitive to differences in the psychological distances between social ranks, which are clearly delineated by the sharp role distinction between student and teacher (and school administration). Hofstede et al. (2010) argue that schools in high powerdistant cultures are teacher-centered and strictly disciplined. The teacher is seen as the "keeper of the knowledge," and students' learning gains are largely attributed to the excellence of his or her teacher. In low power-distance cultures schooling is more learner-centered and teachers are expected to treat students more as equals. Learning gains are hence attributed to the effective interaction between the student and the teacher, with both sides sharing responsibility for successful learning.

The differences characterizing power distance at schools resonate in the founding philosophies of Eastern and Western school systems. Asian cultures based on Confucian philosophy adhere to the view that social harmony is achieved through education, and a good education is achieved through hard work (Nisbett, 2003; Kumar and Maehr, 2007). According to the Confucian philosophy human ability is malleable, great weight is placed on improving ability through effort (Stevenson and Lee, 1990). At the same time, East Asian schools have also been described as examination driven and traditional-if not old-fashioned-with regards to curriculum and teaching style, and the authority of teachers (Leung, 2001; Fry and Bi, 2013). Teaching is teachercentered, and student involvement is minimal as is group work among students (Fry and Bi, 2013).
In contrast, the Western educational systems are rooted in Socratic philosophy with its emphasis on critical thinking and questioning commonly held beliefs and authorities (Tweed and Lehman, 2002; Nisbett, 2003). This is in stark contrast to the Confucian expectation of utmost respect for authority figures (Tweed and Lehman, 2002). In addition, in the Greek Socratic tradition learning is valued as an end in and of itself; in the Confucian tradition education remains instrumental, and a pragmatic orientation is characteristic for the educational philosophy of schooling. Creating a classroom environment where students' opinions are valued even when they go counter to the teacher's beliefs has been observed to be the strongest predictor of a positive school climate in the West (Vieno et al., 2005).

While the widespread opinion in the West is that learning should be an enjoyable experience in its own right, Eastern cultures tend to emphasize the austerity of the learning process and the joy that comes from reaching the aspired educational goal. As a result, many Asian students come to dislike schooling (Leung, 2001). Although immigrant research cannot be generalized to cross-national differences (see Oyserman et al., 2002), Zusho et al. (2005) have noted that Asian American students reported higher fear of failure and anxiety toward mathematics than their Caucasian peers-despite their higher achievement.

Furthermore, for many Asian students competition for elite academic placement is intense and a significant source of stress (Zeng and Le Tendre, 1998; Kumar and Maehr, 2007). While in the West, most pedagogical philosophies highlight the importance of intrinsic motivation (Deci and Ryan, 1985), extrinsic motivation is held in high regard in East Asia where examinations are highly competitive and teaching is oriented toward testing to an extent that many Western teachers consider limiting and inappropriate (Leung, 2001). Thus, while Asian cultures as a whole promote interdependence, the school contexts tend to emphasize individual competition even more than in the West.

Competition and focus on demonstrating ability by outperforming others (as reported by both students and teachers) has been related to decreases in sense of belonging (Anderman and Anderman, 1999; Kumar, 2006). Kumar et al. (2002) note that emphasis on performance goals (i.e., demonstrating ability relative to peers' ability instead of focusing on ability relative to personal standards) is in part communicated to students by frequent testing. Thus, despite the overall emphasis on collective values, it is possible that the emphasis on hierarchical structure (i.e., larger power distance) and outperforming one's peers in East Asian schools results in lower school belongingness compared to Western countries.

\section{Belongingness and Teaching Practices}

Despite these cultural differences, there is reason to believe that some aspects of schooling are experienced similarly regardless of the cultural context. Osterman (2000) noted that the experience of belonging at school requires that the students feel that the teacher respects them and has positive expectations of them. Teachers who emphasize prosocial values and cooperation, are caring, and downplay the importance of extrinsic rewards have students who are more engaged, which in turn increases students' sense of belonging (Solomon et al., 1996). Indeed, teacher 
support has been found to be one of the most robust predictors of school belongingness (e.g., Roeser et al., 1996; Faircloth and Hamm, 2005), and several measures of belongingness include teacher support as one of the components of the overall school belonging (e.g., Goodenow, 1993; Gest et al., 2005; Van Ryzin et al., 2009). Although most of the research has been conducted in the USA, a recent study looking at teachers' beliefs about mathematics teaching revealed that Chinese teachers mentioned good student-teacher relations as a feature of optimal teaching even more often than the US teachers (Correa et al., 2008).

Teaching practices emphasizing cooperation over competition have also been linked to better peer relations (Solomon et al., 1996; Osterman, 2000; Slavin, 2015), and this pattern has been found to hold across countries (Roseth et al., 2008). Following the social interdependence model to explain the positive impact of cooperation on student well-being and achievement (Johnson et al., 2008; Slavin, 2015), it is the sense of cohesion that creates a positive learning atmosphere that drives its positive impact. This atmosphere is dependent more on the students understanding of-and preference for-cooperation than the level of actual cooperation observable in the classroom. Consistent with this conceptual understanding, a study looking at German, Canadian, and Iranian students revealed that all students preferred cooperative learning environments to competitive learning environments and showed higher performance in cooperative settings (Huber et al., 1992).

Therefore, while East Asian school culture may emphasize competition more than Western school culture does, we would still expect that most students personally prefer cooperative learning over competition, and it should be related to higher school belongingness.

\section{The Present Study}

In this study, we investigated how universal the patterns for students' sense of belonging are from an international comparative perspective. We tested the following three hypotheses:

(1) Countries vary substantially in the level of school belongingness students report.

(2) The larger power distance in schools and the emphasis on outperforming peers overrides the cultural collective norm. East Asian students report lower school belongingness.

(3) The underlying psychological mechanisms follow the same pattern irrespective of culture. Specifically, we predicted that positive teacher student relations and a preference for cooperative learning situations predict heightened school belongingness regardless of the culture.

\section{MATERIALS AND METHODS}

\section{Participants}

The analyses for the study were conducted using the 2003 Programme for International Student Assessment (PISA) survey data. Our sample included 86,814 students from 3,182 schools and 31 countries. We excluded USA because it did not include the belongingness scale in the PISA 2003 questionnaire and France because of missing school level data.
PISA is a cyclical international academic achievement monitoring study under the tutelage of Organization for Economic Co-operation and Development (OECD, 2010). Following strict guidelines, each participating country collects achievement test and questionnaire data on representative samples of 15-year-old students. In 2003, the main focus lay on mathematics literacy skills and math instruction. Fifteen-year olds are of particular interest to belongingness research because adolescence as a developmental period has been characterized by a strong need for belonging (Battistich et al., 1997), and adolescents become increasingly dependent on their social groups, some relying even more on their peers than on their parents (Fuligni et al., 2001). Mean age of the participating students was 15.8 years (SD 0.28); $50.4 \%$ of the students were male. PISA student weights were used throughout the analyses to secure national representativeness for the target population in each country and to allow for comparisons across nations. More information about sampling and consent procedures is available in the PISA 2003 technical report (OECD, 2005).

\section{Measures}

In addition to measuring the students' skills in mathematics, reading, and scientific literacy, PISA includes a student questionnaire on different aspects of their academic lives, including motivational and affective measures. The variables we included in our analysis are described below. Standard demographic variables were also available.

\section{Individual Level}

We included school belongingness, preference for cooperative or competitive learning, and gender at the individual level.

\section{School Belongingness}

School belongingness as outcome variable was measured with a six-item scale using the items "My school is a place where..." (1) "I feel like an outsider (or left out of things)," (2) "I make friends easily," (3) "I feel like I belong," (4) "I feel awkward and out of place," (5) "Other students seem to like me," and (6) "I feel lonely." Students rated their responses on a Likert scale ranging from 1 (strongly agree) to 4 (strongly disagree). Items 1,4 , and 6 were reverse-coded. We calculated the reliability for the school belongingness scale using both weighted and un-weighted student scores. Cronbach's alpha reliability estimates by country are presented in Table 1. With the exception of Turkey, Tunisia, and Indonesia, all reliabilities meet or exceed 0.70 .

As noted earlier, some belongingness scales include perceived teacher support as part of the scale (Goodenow, 1993; Gest et al., 2005; Van Ryzin et al., 2009). Conceptually, this is unfortunate since it obscures a causal relation by making the cause an indicator of the effect. Furthermore, studies that have kept teacher and peer relationships as separate constructs have found that teacher variables act both as mediators and moderators between peer acceptance and student behavior (Chang et al., 2004). Therefore, we followed the tradition of researchers who measured these constructs separately (e.g., Guay et al., 1999; Ma, 2003; Maestas et al., 2007).

\section{Teacher-Student Relations}

Teacher-student relations were assessed using a 5-item Likert scale. Examples are "Students get along well with most teachers" 
TABLE 1 | Reliability of PISA 2003 school belongingness scale.

\begin{tabular}{|c|c|}
\hline Country & Reliability \\
\hline Australia & 0.849 \\
\hline Austria & 0.813 \\
\hline Belgium & 0.761 \\
\hline Brazil & 0.800 \\
\hline Canada & 0.854 \\
\hline Switzerland & 0.773 \\
\hline Republic of Czech & 0.735 \\
\hline Germany & 0.806 \\
\hline Denmark & 0.784 \\
\hline Spain & 0.788 \\
\hline Finland & 0.859 \\
\hline France & 0.759 \\
\hline Great Britain & 0.838 \\
\hline Greece & 0.758 \\
\hline Hong Kong (China) & 0.736 \\
\hline Hungary & 0.793 \\
\hline Indonesia & 0.548 \\
\hline Ireland & 0.824 \\
\hline Iceland & 0.855 \\
\hline Italy & 0.786 \\
\hline Japan & 0.758 \\
\hline Korea & 0.749 \\
\hline Lithuania & 0.822 \\
\hline Luxemburg & 0.776 \\
\hline Latvia & 0.737 \\
\hline Macao (China) & 0.754 \\
\hline Mexico & 0.718 \\
\hline Netherlands & 0.754 \\
\hline Norway & 0.832 \\
\hline New Zealand & 0.833 \\
\hline Poland & 0.750 \\
\hline Portugal & 0.775 \\
\hline Russia & 0.733 \\
\hline Slovakia & 0.768 \\
\hline Sweden & 0.825 \\
\hline Thailand & 0.697 \\
\hline Tunisia & 0.689 \\
\hline Turkey & 0.552 \\
\hline Uruguay & 0.792 \\
\hline Yugoslavia & 0.732 \\
\hline
\end{tabular}

and "Most of my teachers really listen to what I have to say." The response scale was identical to the belongingness scale, and Cronbach's alphas exceed 0.73 for the countries.

Preference for Cooperative/Competitive Learning Environment Preference for cooperative/competitive learning environment was assessed with reference to mathematic instruction. Students were asked to what degree they agree with ten statements such as "I would like to be the best in my class in mathematics," "I try very hard in mathematics because I want to do better in the exams than the others" (competitive learning situation preference), and "I do my best work in mathematics when I work with other students" and "In mathematics I learn most when I work with other students in my class" (cooperative learning situation preference). Both scales consisted of five items. The response scale was identical to the belongingness scale, and reliabilities exceed 0.69 for cooperative learning climate preference (except for Indonesia) and 0.70 for competitive learning climate preference.

\section{Gender}

Gender was used as a control variable (girls were coded as 1 and boys as 2). Studies reporting on gender differences often find that girls experience higher school belongingness than boys (e.g., Goodenow, 1993; Anderman, 2002; Ma, 2003). However, it is not clear how consistent this finding is outside the Western school context. For example, no gender differences were reported in school belongingness in a sample of Latino students in the USA (Sanchez et al., 2005) or in a sample of Chinese students in China (Liu and Lu, 2011).

\section{School Level}

\section{School Quality of Student-Teacher Relations}

We created an average score for student teacher relations at the school level from the individual reports as an indicator of general student-teacher climate in the schools. The other school-level measures came from questionnaires distributed to the principals.

\section{School Size}

School size was introduced as control variable without a directed prediction since empirical findings regarding its effect of belongingness are inconclusive: some studies reveal a beneficial effect of smaller schools (Lee and Loeb, 2000), others suggest benefits from attending a larger school (Rumberger and Thomas, 2000), and still others have found no relation between school size and belongingness (Battistich et al., 1997; Anderman, 2002). In the PISA data, school size was reported as total enrollment of 15-year olds (see PISA technical report for further detail, OECD, 2005).

Principals' reports of school autonomy were included on an exploratory basis. Deci (2009) has noted that giving schools more leeway in the way it is run should result in a better psychological climate throughout, arguing that psychological influences at the administration level may trickle down to teachers and then students. Giving more autonomy to the teachers and staff would also be consistent with low power distance using Hofstede's cultural dimensions. Accordingly, we expected that higher curricular and resource autonomy would predict higher reports of school belongingness.

\section{Resource Autonomy}

Resource autonomy was measured with two subscales: The first subscale consisted of 10 questions with reference to the question "In your school, who has the main responsibility for..." "selecting teachers for hire?", "formulating the school budget?," "approving students for admittance to the school?," etc. There were five answer choices: "Not a main responsibility of the school," "School's $\langle$ governing board $\rangle$," "Principal," "〈Department head $\rangle$," and “Teacher(s)." In addition, the principals were asked to indicate which of a list of national or regional agencies have direct influence on the aforementioned decisions, Cronbach's alpha $=0.78$.

\section{Curricular Autonomy}

With a format similar to resource autonomy, the principals were asked to report how much influence the school has on decisions regarding assessment policies, textbook choices, course content, 
and course offerings. The answer key was similar to the curriculum autonomy questionnaire described above, Cronbach's alpha $=0.74$.

\section{Competitive Admission}

A limitation of the PISA 2003 data for the present study is that it does not directly measure the perceived competition on the school level. As a proxy for this characteristic we included the principals' reports of competitiveness in student admission, based on the assumption that if high consideration is given to academic achievement in admission, competition is also likely to be a pervasive feature in the school culture, and hence conducive to competition among students. The item we used was "How much consideration is given to [Student's academic record] when students are admitted to your school?" The answer choices were "Pre-requisite," "High priority," "Considered," and "Not considered," coded 1 to 4 .

\section{Country Level}

Country-level data were drawn from the publicly available cultural dimensions dataset and from World Bank web site.

\section{Cultural Context}

The critical predictors in our study were the cultural origin of the country and the degree to which the culture emphasizes individualism/collectivism and power distance. These measured were taken from the publicly available cultural dimensions data set. The cultural dimensions were originally identified by Hofstede (2001) via factor analysis. Using average factor scores, each country can be represented by the mean vector for the five cultural dimensions (Hofstede, 2001).

\section{Individualism/Collectivism}

Each pole of the individualism/collectivism dimension is characterized by the relative importance employees attach to work goal items. On the individualism side of this polar construct, high-scoring items refer to personal time (time off job to pursue own interests), freedom (to adopt own approach on the job), and challenge (for which you can gain a personal sense of accomplishment). On the collectivist end of the dimension, the important goals are training (to improve skills), physical conditions (e.g., good ventilation and adequate working space), and use of skills (to be able to use one's skills fully). The data suggest that when people rate the first one of these goals highly, they are also likely to rate the other two highly. The individualistic goals emphasize employees' separateness from the employer, and the collectivist goals emphasize employees' dependence on the organization. Countries included in the data set range from an individualism score of 6 (lowest: Guatemala) to 91 (highest: USA).

\section{Power Distance}

The three items that compose the power distance index were nonmanagerial employees' perception of the frequency of employees being afraid to express disagreement with the managers, subordinates perception of the boss' decision-making style, and subordinates preference for boss' decision-making style. Countries included in the dataset range from a power distance score of 11 (Austria) to 102 (Malaysia, not included in the PISA data).

\section{Wealth of the Country}

Wealth of the country was used as a control variable. Poverty has been negatively associated with sense of belonging to the school in the USA so that sense of belonging is weaker in poor areas compared to more affluent areas (Battistich et al., 1995, 1997). We used the percentage of GDP spent on education as a relevant measure of wealth. The measure was taken from the Word Bank database for year 2007.

\section{Statistical Method}

We used hierarchical linear modeling (HLM) to analyze the data (Raudenbush and Bryk, 2002). HLM is particularly suitable for this type of data where students are nested within schools, which are nested within countries (Lubbers et al., 2006; Hamm and Zhang, 2010). Accordingly, we used a three-level HLM model with students as unit of analysis on level 1, schools at level 2, and countries at level 3. Using HLM allows us to distinguish effects of individual behavior from context effect of the school environment while taking into account that nested data are not independent of each other within each higher order unit (Goldstein, 1995). Weighted data were used in all of the analysis. Some countries purposefully oversample subpopulations of interest (e.g., students from rural areas and minority students), and we thus used the student weights provided by PISA to adjust for sampling differences across nations. The weighted data are considered representative of the target student population in each country.

\section{RESULTS}

Most of the variability (89\%) was at the individual level, i.e., between students within schools; $2.4 \%$ of the variance is associated with the school level; and $6.9 \%$ of the variance reflects differences in the mean sense of belongingness across countries (Table 2, Model 1). Note that there is more variance between countries than between schools within a given country.

Models 2-4 in Table 2 summarize the findings for a sequence of analyses including predictors from level 1 (Model 2), adding predictors of level 2 (Model 3) and finally (Models 4a and 4b) adding predictor variables that reflect differences between nations. The coefficients for school and country level predictors were standardized and represent the effects associated with $1 \mathrm{SD}$ change in the predictor variable.

Model 2: On the student level, the perceived quality of the student-teacher relations $(0.217, p<0.01)$ and preference for cooperative learning environment $(0.171, p<0.01)$ are significant predictors of students' sense of belongingness. Students who report experiencing more positive student teacher relations are likely to report higher level of school belongingness. Students who prefer cooperative learning arrangements tended to report higher school belongingness across the multinational sample. Neither students' gender nor preference for competitive learning environment was significantly associated with sense of belongingness. 
TABLE 2 | Predictors of school belongingness.

\begin{tabular}{|c|c|c|c|c|c|c|c|c|c|c|}
\hline Outcome: school belongingness & $\begin{array}{c}\text { Model 1: } \\
\text { unconditional }\end{array}$ & $p$ & $\begin{array}{c}\text { Model 2: } \\
\text { student } \\
\text { factors }\end{array}$ & $p$ & $\begin{array}{l}\text { Model 3: } \\
\text { school } \\
\text { factors }\end{array}$ & $p$ & $\begin{array}{c}\text { Model 4a: } \\
\text { country } \\
\text { factors }\end{array}$ & $p$ & $\begin{array}{c}\text { Model 4b: } \\
\text { country } \\
\text { factors }\end{array}$ & $p$ \\
\hline \multicolumn{11}{|l|}{ Level 1: student variables } \\
\hline Intercept & -0.046 & 0.356 & -0.078 & 0.109 & -0.083 & 0.105 & -0.081 & 0.074 & -0.079 & 0.060 \\
\hline Student-teacher relation & - & & 0.216 & 0.000 & 0.217 & 0.000 & 0.217 & 0.000 & 0.217 & 0.000 \\
\hline Preference cooperative learning & - & & 0.171 & 0.000 & 0.171 & 0.000 & 0.171 & 0.000 & 0.171 & 0.000 \\
\hline Preference competitive learning & - & & -0.006 & 0.314 & -0.005 & 0.328 & -0.005 & 0.403 & -0.005 & 0.329 \\
\hline Gender & - & & 0.019 & 0.160 & 0.019 & 0.162 & 0.019 & 0.165 & 0.019 & 0.162 \\
\hline \multicolumn{11}{|l|}{ Level 2: school variables } \\
\hline School size & - & & - & & 0.033 & 0.000 & 0.033 & 0.000 & 0.033 & 0.000 \\
\hline Student-teacher relation (mean) & - & & - & & -0.000 & 0.993 & -0.000 & 0.992 & -0.000 & 0.976 \\
\hline Resource autonomy & - & & - & & 0.022 & 0.005 & 0.021 & 0.006 & 0.021 & 0.006 \\
\hline Curricular autonomy & - & & - & & -0.012 & 0.135 & -0.013 & 0.124 & -0.013 & 0.121 \\
\hline Competitive admission & - & & - & & -0.025 & 0.034 & -0.025 & 0.032 & -0.025 & 0.033 \\
\hline \multicolumn{11}{|l|}{ Level 3: country variables } \\
\hline GDP on education & - & & - & & - & & 0.080 & 0.212 & 0.020 & 0.774 \\
\hline Individualism & & & & & & & 0.098 & 0.045 & 0.060 & 0.282 \\
\hline Power distance & & & & & & & - & - & -0.120 & 0.048 \\
\hline Level 1: variance $\sigma^{2}$ & 0.870 & & 0.790 & & 0.790 & & 0.790 & & 0.790 & \\
\hline Level 2: variance $\tau^{\pi}$ & 0.024 & 0.000 & 0.019 & 0.000 & 0.018 & 0.000 & 0.018 & 0.000 & 0.018 & 0.000 \\
\hline Level 3: variance $\tau^{\beta}$ & 0.069 & 0.000 & 0.071 & 0.000 & 0.080 & 0.000 & 0.056 & 0.000 & 0.048 & 0.000 \\
\hline
\end{tabular}

Adding school predictor variables (Model 3) did not substantially affect the coefficient of the effect on level one. Higher school belongingness was in addition predicted by larger school sizes $(0.033, p<0.01)$ and by principal's reports of resource autonomy $(0.021, p<0.01)$. In other words, students in larger schools tended to report higher belongingness than students in smaller schools, and in schools where the principal felt that the school had high autonomy over school resources students also reported higher belongingness. Because the school- and country-level variables were standardized, the coefficient for school size indicates that every 1 SD increase in the school size ( 1 SD $=576$ students) results in 0.032 points higher reports of school belongingness. As predicted, our proxy for the competitive atmosphere of the school (competitive admission) was negatively associated with school belongingness $(-0.025, p<0.05)$. Principal reports on curricular autonomy did not have an effect on school belongingness, nor did teacher student relations when they were averaged across the students in one school.

Our central hypothesis concerned the country-level influences on belongingness: individualism/collectivism and power distance. As Model 4a reveals, we found a significant effect rejecting hypothesis 2a, supporting 2b: Students in more individualistic (Western) countries reported higher belongingness than students in collectivist, Asian countries $(0.098, p<0.05)$. Consistent with Hofstede's model, this effect is reduced to non-significance once power distance is added to the model (4b). In the full model power distance negatively predicts school belongingness $(-0.120$, $p<0.05$ ), supporting the hypothesis that school cultures in which hierarchies are more pronounced students experience less sense of belongingness to the school. The percentage of GDP spent on education did not affect students' school belongingness.

Figure 1 illustrates the levels of school belongingness by country, centered around the overall mean of the data set. With very few exceptions (notably Belgium²), Western countries score consistently above average while all East Asian countries in this study scored below average. It is noteworthy that, in keeping with the cultural dimensions hypothesis, the country with the lowest power distance score according to Hofstede (Austria) is also the country with the highest mean school belongingness.

Although preliminary analyses had indicated that principals from East Asian schools gave significantly more consideration to student's prior academic achievement $(M=2.18)$ than principals from Western schools $(M=3.46, F=126.57, p<0.000)$, adding the competition proxy to the full model did not reduce the power distance effect. To further explore the effect of competitive admission on school belongingness, we also explored the effect of adding an interaction term (competition $\times$ East/West) in the model. The interaction was not significant, suggesting that the effect of competitive admission on school belongingness did not differ depending on whether the country was culturally Western or Eastern. The interaction term is not included in the present model.

\section{DISCUSSION}

The purpose of the study was to test hypotheses for patterns of school belongingness in a cross-cultural sample, particularly focusing on Western and East Asian students. We started by discussing the literature on cross-cultural psychology which

\footnotetext{
${ }^{2}$ One reason for this may be that there is something about the French translation of the belongingness scale that slightly changes the meaning of the items. For example, the English item "I feel like I belong" is "Je me sens chez moi" in the French version of the questionnaire, and this can be also understood as "I feel at home". Looking at school belongingness by language group in Belgium also reveals that while Flemish and French speaking students report lower than average school belongingness, German-speaking students reports higher than average belongingness, suggesting that it indeed may be an issue related to translation.
} 


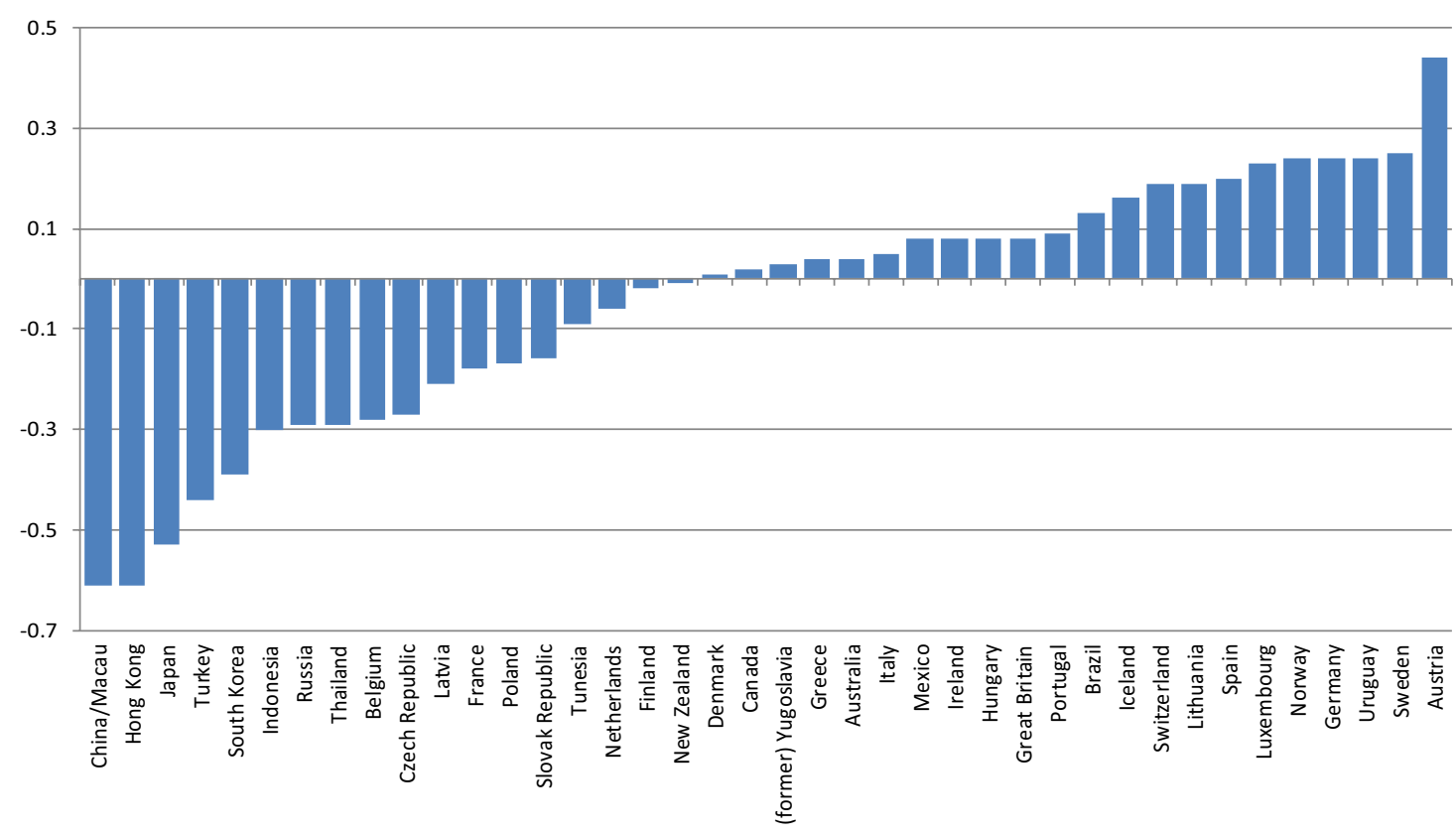

FIGURE 1 | School belongingness by country (z-scores)

makes prediction about differences on the sense of self between (collectivist) Asian and (individualistic) Western cultures; students living in collectivist cultures would report higher school belongingness. Drawing on the cultural dimensions work by Hofstede et al. (2010) we derived the opposite hypothesis based on the premise that schools define an institutional context where power distance (i.e., social hierarchy) shapes social relationships.

The findings strongly support Hofstede's perspective: Not only did the mean scores differ in the predicted direction, but there were also almost no exception to the East-West divide. On the country level, the distributions of East Asian countries and Western countries do not overlap. Given that within each group the questionnaire was given in many different languages, it is unlikely that this effect is an artifact of item translation, a problem we identified for the French version of the questionnaire. It is also noteworthy that the differences in belongingness are also substantial in terms of effect size: The national belongingness score for Austria is over 1 SD higher than the score for Japan. It is striking that the country effect statistically disappears once the power distance score is held constant suggesting that this might be a key construct to explain the belongingness differences across countries.

The results did not support the hypothesis derived from the cross-cultural literature, but this should not be taken as evidence that the theory itself is inaccurate. The distinction between individualistic and collectivist values has been proven useful in numerous psychological studies ranging from experiments (e.g., Kitayama et al., 2000) to qualitative research (e.g., Stevenson and Lee, 1990). Our finding only suggests that the school as social environment is probably better characterized by its organizational setup and constraints and the cultural difference in the understanding of assigned roles-student and teacher in this case. These findings lend support to Bronfenbrenner's (Bronfenbrenner, 1977, 1979) ecological model which suggests that the more proximal context (school) has a stronger effect on individual's cognition and behaviors than the more distal framework (here: general culture).

Power distance as salient aspect of this environment is also interpreted as a cultural difference that can be traced back to Confucian versus Socratic tradition (Nisbett, 2003). Power distance refers to interaction in institutional contexts and is not a personality trait in the sense of a personal value. While rooted in the same historic difference, individualism/collectivism and power distance are distinct constructs and at least for the aspect of school belongingness the latter eclipses the effect of the former. The collectivist nature of Asian societies in contrast to the salience of individualism in Western societies expresses itself in various aspects of modern societies, but it does not seem to permeate the school as a distinct social setting. Our study suggests that cultures where relationships between subordinated and ordinates (e.g., bosses and employees and teachers and students) are perceived as more equal foster higher belongingness than cultures where there is strict hierarchy. Our findings are also in agreement with a recent Dutch study which found that international students from high power distance countries reported lower social adjustment and attachment to the educational institutions than students from low power-distance countries (Rienties and Tempelaar, 2013).

One alternative explanation why we were unable to find support for the cultural context perspective has to do with whom the student views as in-group. As noted earlier, Triandis (2001) has argued that people in collectivist cultures give priority to ingroup goals. The cultural context hypothesis implicitly assumed that students would view their classmates as their in-group, and 
accordingly report higher sense of school belongingness, but this assumption may be culturally biased. In the Western culture, adolescence is a period where peers surpass parents in their influence on children's attitudes and behavior (Fuligni et al., 2001), but it may be possible that for Asian adolescents the family remains the dominant referenced group despite the fact that students spend a lot of time with their classmates. Notion of collectivity and highly prosocial behavior applies primarily to in-group members, so that being prosocial and considerate to family members but very competitive in school is not contradictory if peers are seen as out-group (Triandis, 1989).

That students' most salient in-group is in fact the family and not their peers is supported by Markus and Kitayama (1991) who note that academic motivation in the East is partly other-motivated, and the child has a desire not only to fit into the group (here: the family) but also to enhance the social standing of the family by excelling in school. In agreement with this argument, Asian students studying in Australia have been observed to consider social approval from their family as a more important contributor to academic motivation than their Australian-born peers (Niles, 1995). Thus, while striving for excellence may distance a child from her classmates at school, it will enhance her experience of feeling closeness to her family.

Note that the results of this study do not suggest that Asian students suffer from lower psychological well-being. Although inclusion in peer groups is particularly important in adolescence in Western cultures (Fuligni et al., 2001; Newman and Newman, 2001), 15-year olds also have the cognitive capacity to realize that social identity operates differently in different contexts (Kumar and Maehr, 2010), and peer relations develop and flourish outside the school contexts. In a similar vein, Crystal et al. (1994) compared American, Japanese, and Chinese high-school students and reported that findings regarding psychological maladjustment (as measured by stress, anxiety, aggression, depressed mood and somatic complaints) did not support the hypothesis that Asian students' higher academic achievement comes at the expense of psychological well-being.

We hypothesized in particular that emphasis on competition in Asian schools may hinder students' sense of school belonging, as suggested by the literature from the achievement goal theory perspective. As expected, our competition proxy was negatively associated with school belongingness in Western countries but positively associated with belongingness in East Asian schools. Therefore, the present results do not suggest that lower school belongingness in East Asian schools is related to emphasis on competition. However, the indicator that we utilized to measure competition on the school level might not be a valid indicator of the construct in East Asian countries like Korea where selectivity is a common element in public education.

In addition to the cultural differences and their association with power distance, we found rather universal predictors of school belongingness that are worth noting. As suggested by prior empirical research, the quality of the teacher-student relations was associated with a sense of belongingness across all countries regardless of the cultural background. Although the strength of the effect varied significantly in further exploratory analysis, it was significantly positive in all countries.
As predicted, we also found that preferring cooperative rather than competitive learning is positively associated with school belongingness on the individual level across cultures. While schools might sometimes purposefully emphasize competition, students appear to prefer cooperative learning situations, which are likely to facilitate their sense of social connectedness in schools (Johnson and Johnson, 1994).

The effects of school size on belongingness have been mixed in the empirical literature (Battistich et al., 1997; Lee and Loeb, 2000; Rumberger and Thomas, 2000; Anderman, 2002). In the present study, we found that larger school sizes were associated with higher belongingness within countries. The effect of the school size on belongingness was small, however. In addition, what is considered a "large school" can vary significantly from country to country, making this finding less meaningful cross-culturally. For example, participating schools in Norway had on average just below 300 15-year-old students (with largest schools having 600 students), whereas the mean school size in New Zealand was almost 1,000, with their largest schools having over 3,000 pupils of this age.

While female gender has often been associated with higher reports of school belonging (e.g., Goodenow, 1993; Anderman, 2002; Ma, 2003), we did not find significant gender differences with the PISA data after controlling for differences on perceived teacher support and other variables in the model. Like the achievement gap that favors girls in developed countries and boys in developing countries (United Nations Development Programme, 2006), the gender effects on school belongingness is small by comparison and dependent on the larger cultural context.

\section{Limitations}

The PISA data sets have several strengths. For example, unlike most cross-cultural studies, they are not based on convenience samples. They have, however, some important limitations that should be considered when interpreting the present findings.

Most importantly, we have relatively few indicators of the school-level climate, and no questions directly assessed the perceived competitive atmosphere in schools from the students' perspective. We did not aggregate the student-level questions at school level because they measured preference for competitive and cooperative learning rather than perception of the prevailing climate. Another limitation is that these two items referred specifically to the mathematics classes, while the other measures we included referred to the global atmosphere in the school. Furthermore, PISA relies on self-reported data; students' and principals' responses could not be validated through independent sources. In fact, apart from the aggregated scores, the school-level data are collected from principals only and thus reflect the views and values of only one person per school. This might explain why we did not find an effect of emphasis on competition on the school level sense of belongingness. While an important asset of the PISA data is that it allows the use of identical, back-translated questionnaires for each country instead of proxy measures, the possibility that the translations slightly changed the meaning of the questions remains a valid concern.

Finally, although the PISA data represent the thoughts and feelings of an extraordinarily large cohort of 15-year olds, they 
are cross-sectional and correlational in nature and thus do not warrant conclusions about directionality or causality of effects. The PISA data also includes relatively few East Asian countries. A larger sample of Asian countries would have allowed further investigation of the reasons behind the lower school belongingness by investigating variability within the group of East Asian nations.

\section{Conclusion}

The current study documented that the sense of belongingness to classmates is substantially more pronounced in Western cultures compared to East Asian countries. The analyses indicate that differences in power distance as a cultural norm are better at explaining these international differences in school belongingness than the distinction between individualistic and collectivist norms that dominate the discourse in comparative educational research. The study also highlights that there is a rather universal link between school belongingness and a student's perceived

\section{REFERENCES}

Alvarez, P., Johnson, D. R., Inkelas, K. K., Soldner, M., Leonard, J. B., RowanKenyon, H. T., et al. (2007). Examining sense of belonging among first-year undergraduates from different racial/ethnic groups. J. Coll. Stud. Dev. 48, 525-542. doi:10.1353/csd.2007.0054

Anderman, E. M. (2002). School effects on psychological outcomes during adolescence. J. Educ. Psychol. 94, 795-809. doi:10.1037/0022-0663.94.4.795

Anderman, L. H., and Anderman, E. M. (1999). Social predictors of changes in students' achievement goal orientations. Contemp. Educ. Psychol. 24, 21-37. doi:10.1006/ceps.1998.0978

Battistich, V., and Hom, A. (1997). The relationship between students' sense of their school as a community and their involvement in problem behaviors. Am. J. Public Health 87, 1997-2001. doi:10.2105/AJPH.87.12.1997

Battistich, V., Solomon, D., Kim, D., Watson, M., and Schaps, E. (1995). Schools as communities, poverty levels of student populations, and students' attitudes, motives, and performance: a multilevel analysis. Am. Educ. Res. J. 32, 627. doi:10.3102/00028312032003627

Battistich, V., Solomon, D., Watson, M., and Schaps, E. (1997). Caring school communities. Educ. Psychol. 32, 137-151. doi:10.1207/s15326985ep3203_1

Baumeister, R. F., and Leary, M. R. (1995). The need to belong: desire for interpersonal attachments as a fundamental human motivation. Psychol. Bull. 117, 497-497. doi:10.1037/0033-2909.117.3.497

Bergmüller, S. (2013). The relationship between cultural individualism-collectivism and student aggression across 62 countries. Aggress. Behav. 39, 182-200. doi:10.1002/ab.21472

Bronfenbrenner, U. (1977). Toward an experimental ecology of human development. Am. Psychol. 32, 513-531. doi:10.1037/0003-066X.32.7.513

Bronfenbrenner, U. (1979). The Ecology of Human Development: Experiments by Nature and Design. Cambridge, MA: Harvard University Press.

Chang, L., Liu, H., Wen, Z., Fung, K. Y., Wang, Y., and Xu, Y. (2004). Mediating teacher liking and moderating authoritative teaching on Chinese adolescents' perceptions of antisocial and prosocial behaviors. J. Educ. Psychol. 96, 369-380. doi:10.1037/0022-0663.96.2.369

Correa, C. A., Perry, M., Sims, L. M., Miller, K. F., and Fang, G. (2008). Connected and culturally embedded beliefs: Chinese and US teachers talk about how their students best learn mathematics. Teach. Teach. Educ. 24, 140-153. doi:10.1016/j. tate.2006.11.004

Crystal, D. S., Chen, C., Fuligni, A. J., Stevenson, H. W., Hsu, C. C., Ko, H. J., et al. (1994). Psychological maladjustment and academic achievement: a crosscultural study of Japanese, Chinese, and American high school students. Child Dev. 65, 738-753. doi:10.2307/1131415

Deci, E. L. (2009). Large-scale school reform as viewed from the self-determination theory perspective. Theory Res. Educ. 7, 244-252. doi:10.1177/ 1477878509104329 support by the teacher and a preference for cooperative classroom culture.

\section{ETHICS STATEMENT}

The study is based on a publicly available data set of the Organization of Economic Cooperation and Development (OECD). Data collection for the OECD-PISA studies lies in the responsibility of the individual participating countries under the auspices of the OECD.

\section{AUTHOR CONTRIBUTIONS}

KSC developed the conceptual idea and wrote the result section. SA wrote a first draft of the introduction and revised a first draft of the manuscript. JSD worked into the manuscript a large section of the introduction and did the final edits.

Deci, E. L., and Ryan, R. M. (1985). Intrinsic Motivation and Self-Determination in Human Behavior. New York: Plenum.

Eccles, J. S., and Roeser, R. W. (1999). "School and community influences on human development," in Developmental Psychology: An Advanced Textbook, Fourth Edn, eds M. H. Boorstein and M. E. Lamb (Hillsdale, NJ: Erlbaum), 503-554.

Eccles, J. S., and Roeser, R. W. (2011). Schools as developmental contexts during adolescence. J. Res. Adolesc. 21, 225-241. doi:10.1111/j.1532-7795.2010.00725.x

Faircloth, B. S., and Hamm, J. V. (2005). Sense of belonging among high school students representing 4 ethnic groups. J. Youth Adolesc. 34, 293-309. doi:10.1007/ s10964-005-5752-7

Fiske, A. P., Kitayama, S., Markus, H. R., and Nisbett, R. E. (1998). “The cultural matrix of social psychology," in The Handbook of Social Psychology, Vol. 2, eds D. T. Gilbert, S. T. Fiske, and G. Lindzey (New York: Wiley), 915-981.

Fry, G. W., and Bi, H. (2013). The evolution of educational reform in Thailand: The Thai educational paradox. J. Educ. Admin. 51, 290-319. doi:10.1108/09578231311311483

Fuligni, A. J., Eccles, J. S., Barber, B. L., and Clements, P. (2001). Early adolescent peer orientation and adjustment during high school. Dev. Psychol. 37, 28-36. doi:10.1037/0012-1649.37.1.28

Furrer, C., and Skinner, E. (2003). Sense of relatedness as a factor in children's academic engagement and performance. J. Educ. Psychol. 95, 148-162. doi:10.1037/0022-0663.95.1.148

Gest, S. D., Domitrovich, C. E., and Welsh, J. A. (2005). Peer academic reputation in elementary school: associations with changes in self-concept and academic skills. J. Educ. Psychol. 97, 337-346.

Goldstein, H. (1995). Multilevel Statistical Models. London, UK: Edward Arnold.

Goodenow, C. (1993). The psychological sense of school membership among adolescents: scale development and educational correlates. Psychol. Sch. 30, 79-79. doi:10.1002/1520-6807(199301)30:1<79::AID-PITS2310300113>3.0. $\mathrm{CO} ; 2-\mathrm{X}$

Guay, F., Boivin, M., and Hodges, E. V. (1999). Predicting change in academic achievement: a model of peer experiences and self-system processes. J. Educ. Psychol. 91, 105-115. doi:10.1037/0022-0663.91.1.105

Gudykunst, W. B., and Nishida, T. (1986). The influence of cultural variability on perceptions of communication behavior associated with relationship terms. Hum. Commun. Res. 13, 147-166. doi:10.1111/j.1468-2958.1986.tb00099.x

Hamm, J. L., and Zhang, L. (2010). "School contexts and the development of adolescents' peer relations," in Handbook of Research on School, Schooling, and Human Development, eds J. L. Meece and J. S. Eccles (New York: Routledge), $128-145$.

Hofstede, G. (2001). Culture's Consequences: Comparing Values, Behaviors, Institutions, and Organization across Cultures. Thousand Oaks, CA: SAGE.

Hofstede, G., Hofstede, G. J., and Minkov, M. (2010). Cultures and Organizations: Software of the Mind. New York: McGraw-Hill. 
Houtte, V. H., and Stevens, P. A. (2009). School ethnic composition and students' integration outside and inside schools in Belgium. Sociol. Educ. 82, 217. doi:10.1177/003804070908200302

Huber, G. L., Sorrentino, R. M., Davidson, M. A., Eppler, R., and Roth, J. W. H. (1992). Uncertainty orientation and cooperative learning: individual differences within and across cultures. Learn. Individ. Differ. 4, 1-24. doi:10.1016/1041-6080(92)90013-5

Johnson, D. W., and Johnson, R. T. (1994). Learning Together and Alone, Cooperative, Competitive, and Individualistic Learning. Needham Heights, MA: Prentice-Hall.

Johnson, D. W., Johnson, R. T., and Holubec, E. (2008). Cooperation in the Classroom, 8th Edn. Edina, MN: Interaction Book.

Kia-Keating, M., and Ellis, B. H. (2007). Belonging and connection to school in resettlement: young refugees, school belonging, and psychosocial adjustment. Clin. Child Psychol. Psychiatry 12, 29. doi:10.1177/1359104507071052

Kitayama, S., Karasawa, M., Curhan, K. B., Ryff, C. D., and Markus, H. R. (2010). Independence and interdependence predict health and wellbeing: divergent patterns in the United States and Japan. Front. Psychol. 1:163. doi:10.3389/ fpsyg. 2010.00163

Kitayama, S., Markus, H. R., and Kurokawa, M. (2000). Culture, emotion, and well-being: good feelings in Japan and the United States. Cogn. Emot. 14, 93-124. doi:10.1080/026999300379003

Kitayama, S., and Uskul, A. K. (2011). Culture, mind, and the brain: current evidence and future directions. Annu. Rev. Psychol. 62, 419-449. doi:10.1146/ annurev-psych-120709-145357

Kumar, R. (2006). Students' experience of home-school dissonance: the role of school academic culture and perception of classroom goal structures. Contemp. Educ. Psychol. 31, 253-279. doi:10.1016/j.cedpsych.2005.08.002

Kumar, R., Gheen, M. H., and Kaplan, V. (2002). "Goal structures in the learning environment and students' disaffection from learning and schooling," in Goals, Goal Structures, and Patterns of Adaptive Learning, ed. C. Midgley (Mahwah, NJ: Erlbaum), 85-108.

Kumar, R., and Maehr, M. (2010). "Schooling, cultural diversity, and student motivation," in Handbook of Research on Schools, Schooling and Human Development, eds J. L. Meece and J. S. Eccles (New York, NY: Routledge), 308-324.

Kumar, R., and Maehr, M. L. (2007). "Cultural interpretations of achievement motivation: a situated perspective," in Culture, Motivation, and Learning: A Multicultural Perspective, eds F. Salili and R. Hoosain (Charlotte, NC: Information Age Publishing), 43-66.

Lee, V., and Loeb, S. (2000). School size in Chicago elementary schools: effects on teachers' attitudes and students' achievement. Am. Educ. Res. J. 37, 3-31.

Leung, F. K. (2001). In search of an East Asian identity in mathematics education. Educ. Stud. Math. 47, 35-51. doi:10.1023/A:1017936429620

Liu, Y., and Lu, Z. (2011). Trajectories of Chinese students' sense of school belonging and academic achievement over the high school transition period. Learn. Individ. Differ. 21, 187-190. doi:10.1016/j.lindif.2010.12.007

Lubbers, M. J., Van Der Werf, M. P., Snijders, T. A., Creemers, B. P., and Kuyper, H. (2006). The impact of peer relations on academic progress in junior high. J. Sch. Psychol. 44, 491-512. doi:10.1016/j.jsp.2006.07.005

$\mathrm{Ma}, \mathrm{X}$. (2003). Sense of belonging to school: can schools make a difference? J. Educ. Res. 96, 340-349. doi:10.1080/00220670309596617

Maestas, R., Vaquera, G. S., and Zehr, L. M. (2007). Factors impacting sense of belonging at a Hispanic-Serving Institution. J. Hisp. Higher Educ. 6, 20. doi:10.1177/1538192707302801

Markus, H. R., and Kitayama, S. (1991). Culture and the self: implications for cognition, emotion, and motivation. Psychol. Rev. 98, 224-253. doi:10.1037/0033-295X.98.2.224

Markus, H. R., and Kitayama, S. (2010). Cultures and selves A cycle of mutual constitution. Perspect. Psychol. Sci. 5, 420-430. doi:10.1177/1745691610375557

Napoli, M., Marsiglia, F. F., and Kulis, S. (2003). Sense of belonging in school as a protective factor against drug abuse among Native American urban adolescents. J. Soc. Work Pract. Addict. 3, 25-41. doi:10.1300/J160v03n02_03

Newman, B. M., and Newman, P. R. (2001). Group identity and alienation: giving the we its due. J. Youth Adolesc. 30, 515-538. doi:10.1023/A:1010480003929

Niles, F. S. (1995). Cultural differences in learning motivation and learning strategies: a comparison of overseas and Australian students at an Australian university. Int. J. Intercult. Relat. 19, 369-385. doi:10.1016/0147-1767(94) 00025-S
Nisbett, R. E. (2003). The Geography of Thought: How Asians and Westerners think Differentl and Why. New York: Free Press.

OECD. (2005). PISA 2003 Technical Report. Paris: OECD. Available from: http:// www.oecd.org/edu/school/programmeforinternationalstudentassessmentpisa/35188570.pdf

OECD. (2010). PISA 2009 Assessment Framework - Key Competencies in Reading, Mathematics and Science. Paris: OECD.

Osterman, K. F. (2000). Students' need for belonging in the school community. Rev. Educ. Res. 70, 323. doi:10.3102/00346543070003323

Oyserman, D., Coon, H. M., and Kemmelmeier, M. (2002). Rethinking individualism and collectivism: evaluation of theoretical assumptions and meta-analyses. Psychol. Bull. 128, 3-72. doi:10.1037/0033-2909.128.1.3

Patrick, H., Anderman, L. H., and Ryan, A. M. (2002). "Social motivation and the classroom social environment," in Goals, Goal Structures, and Patterns of Adaptive Learning, ed. C. Midgley (Mahwah, NJ: Erlbaum), 85-108.

Raudenbush, S. W., and Bryk, A. S. (2002). Hierarchical Linear Models: Applications and Data Analysis Methods, 2nd Edn. Thousand Oaks, CA: SAGE.

Rienties, B., and Tempelaar, D. (2013). The role of cultural dimensions of international and Dutch students on academic and social integration and academic performance in the Netherlands. Int. J. Intercult. Relat. 37, 188-201. doi:10.1016/j.ijintrel.2012.11.004

Roeser, R. W., Midgley, C., and Urdan, T. C. (1996). Perceptions of the school psychological environment and early adolescents' psychological and behavioral functioning in school: the mediating role of goals and belonging. J. Educ. Psychol. 88, 408-422. doi:10.1037/0022-0663.88.3.408

Roseth, C. J., Johnson, D. W., and Johnson, R. T. (2008). Promoting early adolescents' achievement and peer relationships: the effects of cooperative, competitive, and individualistic goal structures. Psychol. Bull. 134, 223. doi:10.1037/ 0033-2909.134.2.223

Rumberger, R. W., and Thomas, S. L. (2000). The distribution of dropout and turnover rates among urban and suburban high schools. Sociol. Educ. 73, 39-67.

Ryan, R. M., and Deci, E. L. (2000). Self-determination theory and the facilitation of intrinsic motivation, social development, and well-being. Am. Psychol. 55, 68-78. doi:10.1037/0003-066X.55.1.68

Sánchez, B., Colón, Y., and Esparza, P. J. (2005). The role of sense of school belonging and gender in the academic adjustment of latino adolescents. J. Youth Adolesc. 34, 619-628. doi:10.1007/s10964-005-8950-4

Sarason, S. B. (1990). The Predictable Failure of School Reform. San Francisco: Jossey-Bass.

Slavin, R. E. (2015). Cooperative learning in elementary schools. Education 3-13 43, 5-14. doi:10.1080/03004279.2015.963370

Solomon, D., Battistich, V., Kim, D., and Watson, M. (1996). Teacher practices associated with students' sense of the classroom as a community. Soc. Psychol. Educ. 1, 235-267. doi:10.1007/BF02339892

Stevenson, H. W., and Lee, S. Y. (1990). Contexts of achievement: a study of American, Chinese, and Japanese children. Monogr. Soc. Res. Child Dev. 55, 1-123. doi:10.2307/1166090

Sugahara, S., and Boland, G. (2010). The role of cultural factors in the learning style preferences of accounting students: a comparative study between Japan and Australia. Account. Educ. Int. J. 19, 235-255. doi:10.1080/09639280903 208518

Triandis, H. C. (1989). The self and social behavior in differing cultural contexts. Psychol. Rev. 96, 506-520. doi:10.1037/0033-295X.96.3.506

Triandis, H. C. (2001). Individualism-collectivism and personality. J. Pers. 69, 907-924. doi:10.1111/1467-6494.696169

Tweed, R. G., and Lehman, D. R. (2002). Learning considered within a cultural context: confucian and socratic approaches. Am. Psychol. 57, 89-99. doi:10.1037/ 0003-066X.57.2.89

United Nations Development Programme. (2006). Human Development Report, 2006. New York: United Nations Development Programme.

Van Ryzin, M. J., Gravely, A. A., and Roseth, C. J. (2009). Autonomy, belongingness, and engagement in school as contributors to adolescent psychological wellbeing. J. Youth Adolesc. 38, 1-12. doi:10.1007/s10964-007-9257-4

Vieno, A., Perkins, D., Smith, T., and Santinello, M. (2005). Democratic school climate and sense of community in school: a multilevel analysis. Am. J. Community Psychol. 36, 327-341. doi:10.1007/s10464-005-8629-8

Zeng, K., and Le Tendre, G. (1998). Adolescent suicide and academic competition in East Asia. Comp. Educ. Rev. 42, 513-528. doi:10.1086/447526 
Zusho, A., Pintrich, P. R., and Cortina, K. S. (2005). Motives, goals, and adaptive patterns of performance in Asian American and Anglo American students. Learn. Individ. Differ. 15, 141-158. doi:10.1016/j.lindif.2004.11.003

Conflict of Interest Statement: The authors declare that the research was conducted in the absence of any commercial or financial relationships that could be construed as a potential conflict of interest.
Copyright (c) 2017 Cortina, Arel and Smith-Darden. This is an open-access article distributed under the terms of the Creative Commons Attribution License (CC $B Y)$. The use, distribution or reproduction in other forums is permitted, provided the original author(s) or licensor are credited and that the original publication in this journal is cited, in accordance with accepted academic practice. No use, distribution or reproduction is permitted which does not comply with these terms. 